only true system of philosophy by which we can attain the maximum of strength with the minimum of material.

I'he sphere is probably the only true form by which we can obtain uniformity of resistance to an uniform pressure, whether external or internal; and to approximate to this, probably, was the reason why our predecessors, from the days of the Mar-

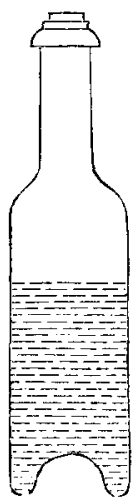
quis of Worcester to those of Watt, adopted the haycock or circular boiler with a hemispherical top and hemispherical bottom, as shown.

This was selected as the strongest

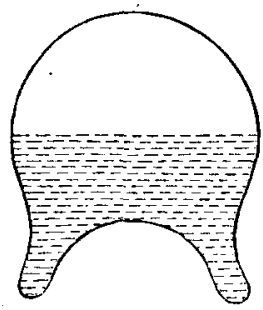
form of boiler in the time of Newcomen and Beighton; and it was probably for a similar reason that the glass-blower forms the bottom of bottles with an elevated cone penetrating for some distance into the interior of the cylindrical part. This gives great strength to the bottle in resisting internal pressure, and at the same time reduces the quantity of liquid contained in the bottle; a consideration independent of strength, and probably a matter of no small importance to the retail dealers in wine and ardent spirits.

For the Journal of the Franklin Institute

\title{
On the durability of Tubes in the Pirsson Condensers.
} By Joseph P. Pirsson.

Messrs. Editors :-My attention has just been called to an article in the Journal of the Franklin Institute for August, entitled "Steam and its Condensation, by Thomas Prosser, C. E.;" and in that article are several statements respecting the operation of my condensers, which I desire briefly to correct. These statements have reference chiefly to the durability of the copper tubes of which the surface portion has been generally constructed.

Mr. Prosser states, that "the copper tubes in the condensers of the Arago were worn out in less than two years. Those in the Keystone State gave out in an incredibly short time. ***** The Fulton fared no better, as regards her condenser tubes," \&c.

'The question of durability in the engines of a sea-going steamer is, of course, a highly important one, and in no part more so than in the condensers.

Want of durability in surface condensers had, until the advent of my invention, been the chief objection to their use; for in all previous attempts, this had been found to involve risks far greater than the advantages to be attained would warrant. The chief elements causing the destruction of the instrument, viz : pressure, and expansion and contraction, I have either totally eliminated, or rendered inuocuous, 
while I have also introduced an entirely new feature in the construction, and upon which only may surface condensation be safely employed. That new feature is the ability to resort to an alternative, in the immediate return to jet-condensation, in case of accident or other necessity. 'The question of durability in the "copper tubes," is reduced therefore to one of economy simply, since their destruction involves that of no element necessary to the working of the engine, and is consequently wholly unattended by risk of any sort.

When the tubes do give out, either in whole or in part, the only difference perceivable in the working of the engine is the loss of fresh water, in proportion to the extent of the defect, this being a feature belonging solely to my invention.

The question of the degree of wear in the surface portion of my condenser, is reduced to that of the selection of the most durable material, and has nothing whatever to do with the principle. 'The copper tubes at present in the condensers of the Arago are now far in the fourth year of their existence, performing in every respect as well as at first. The same is the case in the Fulton, the sister vessel. A few days since, the tubes of the Augusta's condenser were examined and found to be in perfect order, after about four years' use. The United States steamship San Jacinto, having my condensers on board, has just returned from a three years' cruise, and on examination the tubes were found to be in perfect condition, not having in the meanwhile been touched. Mr. Prosser is amused at the idea of there being any advantage in tinning the tubes. On this head I am not committed, one way or the other; and I will merely cite some facts as to the length of time the "tin will remain." $\Upsilon$ do this the more readily, as it will serve to explain the reason why tinning was resorted to at all. At the first introduction of my condensers, I had the misfortune to have several sets of tubes made from Lake Superior copper; for experience was wholly wanting then, as to what effect salt water would have upon this metal, as compared with other copper. It was soon found that it would not stand at all. The Arago had her first set of this copper, and it did not endure for even two voyages; and so too, with the St. Louis. These were replaced by pure Spanish copper, which has proved satisfactory in durability. Messrs. Merrick \& Sons were the first to suggest tinning the tubes, with a view to prolonging their wear, and I believe first treated those in the Quaker City in that way, and other engineers have followed their example. Over four years ago I put into the John $L$. Stevens, 3000 ton vessel, and Sonora, 2400 tons, sets of condenser tubes of pure Spanish copper untinned. These, at late accounts, were still in good order.* Whether the tinning is of any material value, I am unable to say; I have, however, been in favor of it. 'This fact has been proved beyond question, viz: that the condensation is not injuriously affected thereby; while, so far as my observation extends, the tin also adheres to the copper to the last. It would thus seem that the remarks of Mr. Jones, alluded to in Mr. Prosser's article, are fully

* Some, not acquainted with the history of my condengers, may think that I bave been peculiarly unfortunate in having so many vessels with defective tubes. 'Ihese constitute, however, but a fraction of the ships into which they have been introduced, enbracing many of the largest and fnest ever built. 
borne out by the facts cited, as well as that it is important, in an economical point of view, to select the purest kind of copper for the tubes. Additional verification would also appear to be afforded by the result ascertained at the salt works at Salina, New York, where the pans made of this Lake Superior copper have proved very inferior in durability to those of pure Spanish copper.

As these questions are of interest not only to the engineer, but to all connected with ocean steam navigation, I will add that $I$ have also tried brass for the tubes, both tinned and untinned. In the steamship St. Louis, as an experiment, one-half of the tubes were of Spanish copper and one-half of brass, both without being tinned. In the Collins steamship Adriatic, the tubes were of brass, tinned. Their durability in the latter vessel is of course yet to be determined. In the St. Louis, however, thus far, the wear appears to be equal; at least, none of the tubes have worn out, after a period of about four years.

5 Wall street, New York, September Oth, 1858.

\section{On Lighting Railway Trains with Gas; with Description of} Mr. T. J. Thompson's System.* By Mr. KITson.

The lighting of railway trains has received comparatively little attention during the progress and improvements in the railway system, the oil lamp having undergone but few improvements, though its defects have been generally felt. Gas possesses important advantages over all the oil lamp arrangements yet produced, in the constant brilliancy of the light, requiring only two lights for each carriage-the saving that may be effected by turning off lights from all unoccupied carriagesthe brilliant light thereby obtained for the tail and side lights of the train-and the saving in expense.

The first use of gas, to the writer's knowledge, for lighting railway trains, was in the United States, where an arrangement, which seemed to answer, was tried during 1856, upon the Galena and Chicago Railway. Under the floor of each car is placed a gas-holder, consisting of two tubes, each divided into two compartments by a longitudinal diaphragm of india-rubber. Gas is admitted to the tube on one side of the diaphragm from the gas main at the station, thereby pressing the diaphragm against the side of the tube; and the gas is then forced out to the burners by means of a dry metre or small pump, placed on the car, which pumps in air on the other side of the diaphragm, pressing it back against the opposite side of the tube, and thus forcing out the gas. This arrangement has many advantages for an American railway, where a railway car is so much longer than an English carriage, one car accommodating about 70 passengers; and the number of cars therefore required to form a train sufficient to carry 200 passengers amounting to only 3, whereas upon an English line it would require 11 carriages to accommodate the same number of passengers.

* From Newton's London Journal of Arts and Eciencer, A ugust, 1858. 